\title{
Army HIV vaccine to undergo clinical trial as rival is halted
}

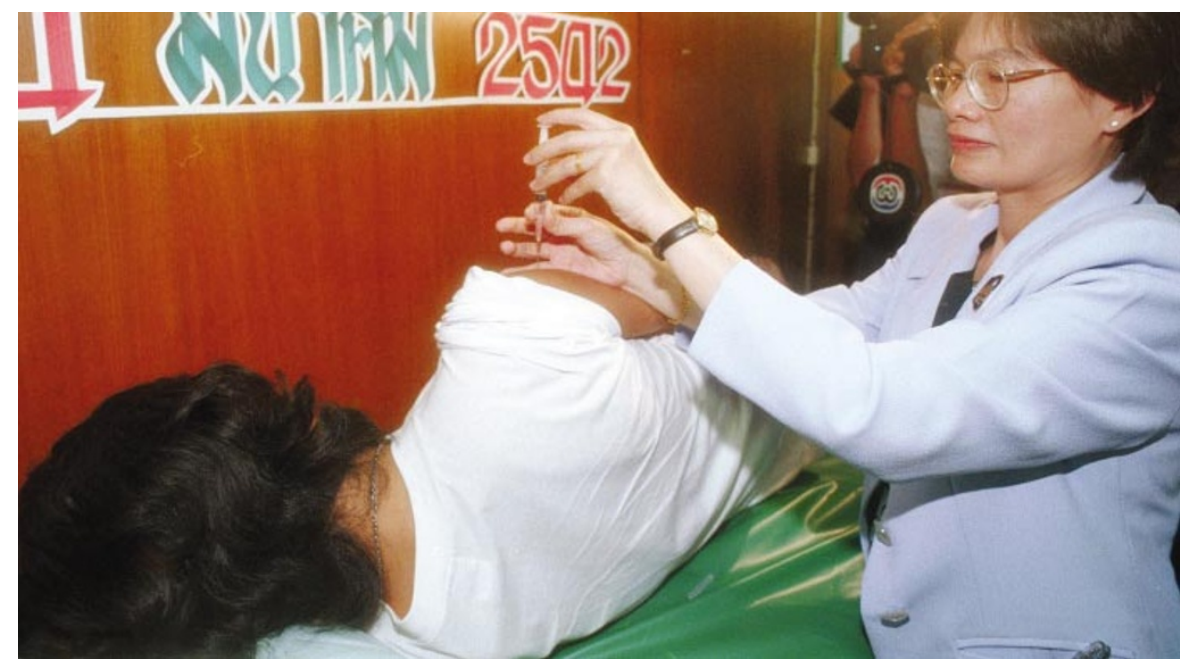

Testing times: Thai volunteers will soon be trying out an HIV vaccine developed by the US army.

\section{Erika Check, Washington}

The National Institutes of Health (NIH) has decided not to proceed with a full-scale clinical trial of its most advanced candidate HIV vaccine because of the vaccine's poor showing in smaller safety and efficacy trials.

But ironically, the NIH will now find itself responsible for running a large-scale study — known as a phase III trial — of a very similar HIV vaccine. This was developed by US Army researchers at the Walter Reed Army Institute of Research in Washington DC, in cooperation with the Thai government.

A January directive from the White House Office of Management and Budget instructs the NIH's National Institute of Allergy and Infectious Diseases (NIAID) to assume responsibility for the army's trial, along with all military HIV/AIDS research, in October. That trial will involve about 16,000 young Thai volunteers and is set to start at the end of the year. The NIH will provide funding for the trial, but other details of the transfer have still to be agreed by the NIH and the army.

Critics have complained that the dual civilian and military trials were a waste of resources (see Nature 415, 365-366; 2002). Both use a 'prime-boost' strategy, which delivers HIV viral proteins in two different ways. The vaccinees are first given a shot of canarypox virus containing HIV genes that code for proteins from the virus' outer coat. This 'prime' shot is followed up by a 'boost' shot of engineered pieces of the protein gp120, which is also found in HIV's coat.

Supporters of the NIH vaccine effort were disappointed that their vaccine had come up short in the smaller, phase II trial. "This is really very unfortunate," says David Baltimore, a molecular biologist and president of the California Institute of Technology, who chairs the NIH's AIDS vaccine research committee. "The development of the HIV vaccine has been excruciatingly slow. It has turned out to be so much more difficult than we originally imagined."

The NIH phase II trial aimed to find out what level of immune response protected vaccinees from the virus. To do that, the vaccine needed to produce a particular immune response in at least $30 \%$ of the volunteers. But the civilian phase II trial "missed that mark by a fair amount", says Anthony Fauci, director of the NIAID. Because the low response will not allow investigators to find out what creates immunity to the virus, Fauci says, that trial did not meet its goal and will not continue.

In contrast, the army's phase III trial will simply evaluate whether the vaccine protects against HIV infection. A spokesperson at Walter Reed says that the appropriate immune response was provoked in $25 \%$ of the volunteers in the phase II military trial. But this result is not strictly comparable to the civilian trialthe army trial used different methods to measure immune responses, for example, and took more frequent measurements in volunteers.

Some researchers think that the army vaccine will be no more effective than the civilian vaccine. But there are other reasons why the army's phase III trial will continue, they say, including the fact that it builds on years of cooperation between the American and Thai governments.

"This trial is more than just a vaccine trial," says Beatrice Hahn, an HIV researcher at the University of Alabama at Birmingham. "They have made such an investment in training, infrastructure, technology transfer, assays and equipment that at this point it's impossible to pull the plug, and no one would want to do so."

\section{Congress seeks to keep Sea Grant in its current harbour}

Virginia Gewin, Washington

Congress is poised to spike a White House plan to transfer the Sea Grant programme from the National Oceanic and Atmospheric Administration (NOAA) to the National Science Foundation (NSF).

The National Sea Grant College Program, which supports research into pollution, sea-food safety and fisheries management, is strongly supported by members of Congress from coastal regions, who want NOAA to stay in charge.

At a hearing on 28 February of a subcommittee of the House of Representatives' science committee, scant support was voiced for the transfer, and four of the five witnesses strongly opposed it. They argued that the hallmark of Sea Grant - its links to local communities and organizations - would be lost if it moved to the NSF.

The House resources committee has already approved a bill that would keep the programme at NOAA for another five years, and the science committee is likely to follow suit. Rick DeVoe, president of the Sea Grant Association, says a bill in the Senate will be developed soon.

"We are optimistic that the House will be able to bring legislation to the floor in the coming months that will reauthorize Sea Grant at NOAA and provide the programme with a robust funding increase," says Carolyn Thoroughgood, president of the Consortium for Oceanographic Research and Education, which lobbies for oceanographic research. But the funding increase, at least, remains uncertain, congressmen say.

If the transfer is derailed in Congress, it will be the second time this year that a plan by the White House Office of Management and Budget to widen the NSF's remit has failed. Its proposed transfer to the NSF of three Smithsonian Institution research centres was abandoned in January(see Nature 415, 252; 2002).

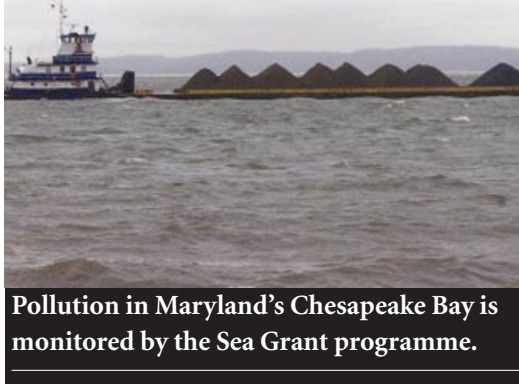

